\title{
Precipitação no extremo norte da Amazônia: distribuição espacial no estado de Roraima, Brasil
}

\author{
Precipitation in northern Amazonia: Spatial distribution in Roraima, Brazil
}

\author{
Paulo Eduardo Barni ${ }^{1}$ \\ Reinaldo Imbrozio Barbosa ${ }^{2}$ \\ Haron Abrahim Magalhães Xaud ${ }^{3}$ \\ Maristela Ramalho Xaud ${ }^{4}$ \\ Philip Martin Fearnside ${ }^{5}$
}

\begin{abstract}
Palavras-chave:
Clima

Pluviosidade

Krigagem ordinária

Modelagem espacial
\end{abstract}

\begin{abstract}
Resumo
A precipitação pluviométrica é uma das variáveis mais importantes para investigações associadas a processos biológicos. Na Amazônia, estudos sobre sua distribuição espacial e temporal vêm sendo utilizados como uma ferramenta de análise no planejamento regional visando a conservação de diferentes ecossistemas. Isto pode ser exemplificado pela construção de calendários agrícolas e de queimas controladas com o objetivo de prevenir que fogos derivados de queimadas para limpeza de roças e pastagens escapem do controle e se transformem em incêndios florestais de grandes proporções em anos de seca severa na Amazônia. O objetivo do estudo foi modelar a distribuição espacial das chuvas no Estado de Roraima (19982018) utilizando as escalas mensal e anual a partir de dados orbitais de dois produtos disponíveis na rede mundial de computadores: TRMM e WORLDCLIM. Foi adotada a krigagem ordinária como método para a modelagem da precipitação com base em 59 estações pluviométricas localizadas em toda a área de estudo. Roraima apresenta dois períodos climáticos bem definidos ao longo do ano (seca e chuva), mas contrastantes em função de seus três tipos climáticos que agem de forma distinta entre dois hemisférios. Em média a precipitação do clima $A f$ (clima equatorial de floresta) se concentra no intervalo entre março e agosto (63,5\%), com pico em maio, enquanto $A m$ (clima de monção) e $A w$ (clima de savana) transitam entre abril a setembro (pico em junho), onde concentram $73,3 \%$ e $82,3 \%$ das chuvas, respectivamente. Entre 1998 e 2018 a precipitação média anual foi
\end{abstract}

1 Universidade Estadual de Roraima - UERR, Campus Rorainópolis. Avenida Senador Hélio Campos, S/N. 69373-000. Rorainópolis, RR.pbarni@uerr.edu.br

2 Instituto Nacional de Pesquisas da Amazônia - INPA, Rua Coronel Pinto, 315. 69301-150, Boa Vista, RR.reinaldo@inpa.gov.br

3 Empresa Brasileira de Pesquisa Agropecuária - Embrapa/RR. Rodovia BR 174, Km 8, Distrito Industrial.69301-970, Boa Vista, RR. haronxaud@gmail.com;

4 Empresa Brasileira de Pesquisa Agropecuária - Embrapa/RR. Rodovia BR 174, Km 8, Distrito Industrial.69301-970, Boa Vista, RR. marisxaud@gmail.com

5 Instituto Nacional de Pesquisas da Amazônia - INPA, Av. André Araújo, 2936. CEP: 69067-375, Manaus, AM. pmfearne@inpa.gov.br 
de $1925 \pm 339,7 \mathrm{~mm}$, independentemente da localização hemisférica. Eventos climáticos extremos possuem um efeito dramático nos índices pluviométricos regionais, fazendo com que em anos El Niño (longas secas) os riscos de incêndios florestais sejam maiores e, em anos de La Niña (períodos de chuva intensa), os riscos de enchentes sejam mais frequentes.

\section{Keywords:}

ClimateRainfall

Ordinary Kriging

Spatial modeling

\begin{abstract}
Rainfall is one of the most important variables for studies of biological processes. In the Amazon, studies on the spatial and temporal distribution of rainfall have been used as an analysis tool in regional planning aimed at the conservation of different ecosystems. This can be exemplified by the construction of agricultural calendars and controlled fires with the objective of preventing the fires that are used to clear fields and pastures from getting out of control and turning into large forest fires in years of severe drought. Our study aimed to model the rainfall spatial distribution in the State of Roraima (1998-2018) at monthly and annual scales based on orbital data from two products available on the world-wide web: TRMM and WORLDCLIM. Ordinary kriging was adopted as a method for modeling precipitation considering 59 meteorological stations located in the study area. Roraima has two well-defined climatic seasons throughout the year, but contrasting due to the state's geographical limit being distributed between two hemispheres. On average, the rainfall of the Af (without dry season) climate is concentrated in the interval between March and August (63.5\%), with a peak in May, while $A m$ (monsoon) and $A w$ (with dry winter) from April to September (peak in June), concentrating $73.3 \%$ and $82.3 \%$ of the rainfall, respectively. Between 1998 and 2018 the average annual precipitation was $1925 \pm 339.7 \mathrm{~mm}$, regardless of the hemispheric location. Extreme climatic events have a dramatic effect on regional rainfall, where El Niño years (long droughts) are characterized as drier periods with higher risks of forest fires, while in La Niña years (wetter periods) there are higher probabilities of heavy rains associated with long periods of flooding.
\end{abstract}

\section{INTRODUÇÃO}

A precipitação pluviométrica é uma das variáveis mais importantes para os processos biológicos e para a conservação da floresta (FEARNSIDE, 2008; BRANDO et al., 2014), podendo ser utilizada como uma ferramenta de análise importante dentro de investigações que associam secas a desmatamentos e incêndios florestais na Amazônia (ARAGÃO et al., 2007; BRANDO et al., 2020). O entendimento da distribuição espacial das chuvas também possui uma ligação muito forte com ações de planejamento regional associadas, por exemplo, à construção de calendários agrícolas e programação de queimas controladas. Nesses dois últimos casos como ações para prevenir que fogos derivados das queimadas escapem do controle e se transformem em incêndios florestais de grandes proporções em anos de seca severa (BARBOSA; FEARNSIDE, 1999; ALENCAR et al., 2006; ARAGÃO; SHIMABUKURO, 2010; XAUD et al., 2013; BARNI et al., 2015a; FONSECA et al.,
2017). Apesar dos recentes avanços representados pela ampliação espacial da rede terrestre de captação de dados e propiciados pelo apoio de diferentes instituições públicas, comunidades indígenas, ribeirinhos e agricultores

(http://www.snirh.gov.br/hidrotelemetria/serieHi storica.aspx), a Amazônia ainda possui grandes áreas de difícil acesso e sem qualquer série histórica provida por meios convencionais (ALVARES et al., 2014). As áreas mais carentes são principalmente representadas pelo extremo norte da Amazônia, em especial o Estado de Roraima.

Um exemplo dessa carência de informações em Roraima pode ser estabelecido pelo fato de que o Governo de Roraima adotava, até recentemente, os dados de frequência de chuvas obtidos apenas da estação meteorológica do INMET (Instituto Nacional de Meteorologia) em Boa Vista para caracterizar o clima de todo o Estado (CASTRO; MIRANDA, 2016; SILVA et al., 2015). Outro forte exemplo é o documento elaborado pelo MDA (Ministério do 
Desenvolvimento Agrário), órgão subordinado à Presidência da República, que caracteriza o clima dos municípios da Região Sul do Estado (BARNI et al., 2012, 2015b), classicamente definido como tropical chuvoso de monção - Am, como Aw, um tipo climático de áreas de savana (MDA, 2010, p. 35 a 57).

Esta situação acaba trazendo prejuízos ao planejamento sócio-econômico-ambiental do Estado de Roraima, inibindo o desenvolvimento da ciência e tecnologia ao desprover o ensino de graduação e pós-graduação de informações meteorológicas corretas e de qualidade científica. Por exemplo, a criação de políticas públicas eficientes para o combate aos incêndios florestais em Roraima passa pela elaboração de calendários agrícolas e de queimas controladas, que requerem informações meteorológicas de qualidade e específicas para cada região climática do Estado.

Embora se tenha registrado importantes avanços nas políticas de combate a incêndios florestais em Roraima nos últimos anos (e.g., FONSECA et al., 2017; CAMMELLI; ANGELSEN, 2019), há de se ressaltar a necessidade constante de busca e aprimoramento de um sistema autorregulado ou automatizado que auxilie nas tomadas de decisões no nível regional. Um desses sistemas locais já existentes é fomentado pelo Comitê de Prevenção e Combate a Incêndios Florestais, instalado em 1999, logo após o grande incêndio de Roraima de 1997/1998 (BARBOSA et al., 2003). Diferente das etapas iniciais, este Comitê vem atualmente sendo alavancado a partir da adesão das comunidades afetadas pelos incêndios florestais com o intuito de fazê-lo funcionar plenamente, protegendo não apenas o patrimônio individual, como também o coletivo, representado pelos serviços ambientais fornecidos pela floresta (e.g. FEARNSIDE, 2013; MEDINA et al., 2015; FONSECA-MORELLO et al., 2017). Como contribuição adicional, o projeto TERRAMZ (Conhecimento Compartilhado para Gestão Territorial Local na Amazônia), em execução pela parceria Embrapa/BNDES/Fundo Amazônia, vem trabalhando na construção de mecanismos participativos de prevenção, monitoramento e controle da degradação florestal por incêndios florestais, buscando avançar nos sistemas (semi)automatizados de monitoramento e alerta de fogo (TERRAMZ, 2020).

Essas iniciativas promissoras compreendem que o esforço para se evitar a perda da biodiversidade e os serviços ambientais da floresta são críticos e devem caminhar no sentido de eliminar as fontes de ignição criadas pelo desmatamento e pelo uso de fogo na manutenção das pastagens e roças e para suprimir as ocorrências de incêndios florestais de sub-bosque (MORTON et al. 2013; SILVA et al., 2018; STAAL et al., 2020).

Nesse contexto, a modelagem da distribuição espacial das chuvas (ou outras variáveis biofísicas) sobre uma superfície regional, que possa servir como base para criação de cenários realísticos e auxiliar na tomada de decisões, é uma alternativa viável à carência de informações provenientes de redes de pluviômetros convencionais (e.g. FONSECA et al., 2017; BRANDO et al., 2020). Ademais, o atual avanço da tecnologia da informação, incluindo as geotecnologias, permitiu uma grande melhoria no grau de certeza de dados obtidos remotamente (PRAKASH et al., 2016), facilitando a aplicação da modelagem espacial a partir de métodos e técnicas de interpolação geoestatística (BACCINI et al., 2012; AVITABILE et al., 2016; BARNI et al., 2016).

Concomitante ao avanço tecnológico observado nesse período, o desenvolvimento de produtos de geoprocessamento utilizando variáveis biofísicas como a temperatura do ar e a precipitação pluviométrica (HUFFMAN et al., 1997; HIJMANS et al., 2005; FICK; HIJMANS, 2017), em escala mundial (WORLDCLIM), por exemplo, surpreendentemente, ajudou a impulsionar também a pesquisa científica no nível local/regional (ALVARES et al., 2014; YANG et al., 2017). Neste contexto o banco de dados gerado pelo satélite tropical de medição de precipitações (TRMM na sigla em Inglês), produzido pela Administração Nacional Aeronáutica e Espacial (NASA, EUA) em parceria com a Agência Espacial Japonesa (JAXA) para estudos da precipitação nos trópicos (PASSOW, 2010; MACRITCHIE, 2015), cumpre um relevante papel em todo mundo (CHEN; LI, 2016; YANG et al., 2017).

Por outro lado, considerando plataformas online que fornecem produtos de sensoriamento remoto para estudos climáticos no Brasil, podemos citar a Companhia de Pesquisa de Recursos Minerais - CPRM (https://www.cprm.gov.br/publique/

Hidrologia/Mapas-e-Publicacoes/Atlas-

Pluviometrico-do-Brasil-1351.html), a Agência Nacional de Águas - ANA (https://www.ana.gov.br/panorama-das-

aguas/divisoes-hidrograficas), o INMET (http://www.inmet.gov.br/portal/) e o Centro de Previsão de Tempo e Estudos Climáticos CPTEC (https://www.cptec.inpe.br/). Essas agências, dentro de suas especificidades (CPRM: mapas de normais climatológicas; ANA: gestão e 
dados de pluviômetros e; INMET e CEPTEC: mapas e análises climáticas), prestam um excelente serviço à sociedade científica brasileira.

Portanto, este estudo teve como objetivo aplicar modelos geoestatísticos à distribuição espacial das chuvas (precipitação pluviométrica) em Roraima (1998-2018) utilizando as escalas mensal e anual a partir de dados orbitais dos produtos TRMM WORLDCLIM, disponíveis na rede mundial de computadores. A partir da modelagem espacial, esse estudo visa construir e disponibilizar para a comunidade científica, uma base de mapas de frequência de chuvas englobando o Estado de Roraima e regiões vizinhas.

\section{MATERIAL E MÉTODOS}

\section{Área de estudo}

Embora a proposta para distribuição espacial da pluviosidade seja restrita ao Estado de Roraima (224.273,8 km²: IBGE, 2020), a sua modelagem requereu informações sobre uma área de 687.072 $\mathrm{km}^{2}(816 \mathrm{~km} \times 842 \mathrm{~km})$ que abrangeu parte dos estados do Amazonas e Pará, além de parte da região sul da Venezuela e oeste da Guiana (Mapa 1). Este procedimento visa evitar ou minimizar "distorções" causadas pelo efeito de borda, comuns na aplicação de técnicas de interpolação geoestatística (BARNI et al., 2016).

Mapa 1 - Área de estudo. As linhas curvas sobre Roraima subdividem a área em três tipos climáticos: $A f$ (clima equatorial de floresta), $A m$ (clima de monção) e $A w$ (clima de savana) de acordo com a classificação de Köppen (BARBOSA, 1997; ALVARES et al., 2014).

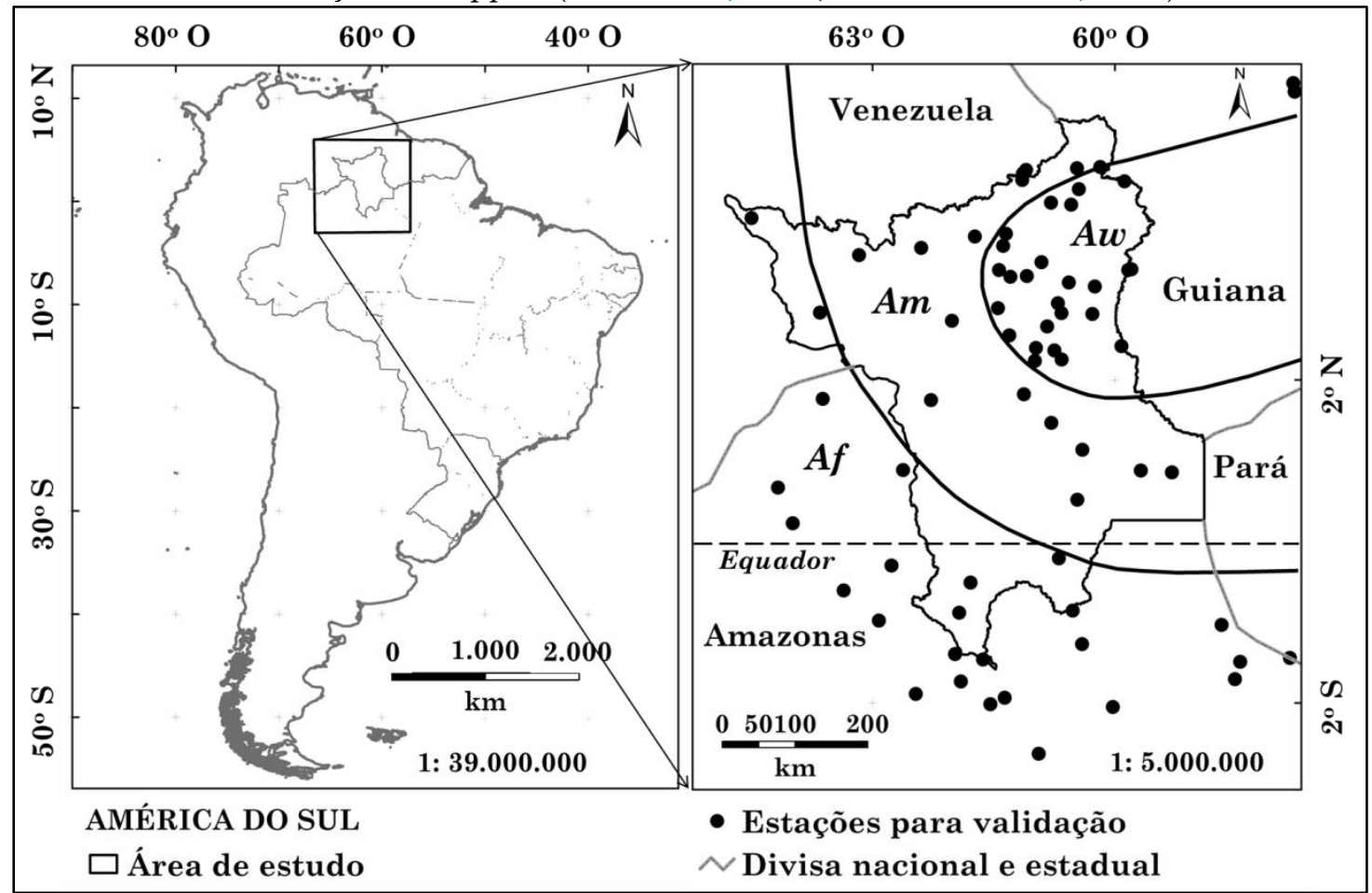

Organizado pelos autores, 2020.

\section{Modelagem espacial}

A modelagem da distribuição espacial e temporal da precipitação no Estado de Roraima foi realizada a partir da confecção de mapas de precipitação do produto TRMM 3B43 (http://trmm.gsfc.nasa.gov/), em Hierarchical Data Format - HDF (formato de arquivo padronizado para armazenamento de dados), com resolução espacial de 0,25 graus $(\sim 27,75 \mathrm{~km}$; $\left.1^{\circ} \sim 111 \mathrm{~km}\right)$ e de mapas do WORLD CLIM (http://www.worldclim.org/current), no formato raster (grade de células), com resolução espacial de 10 minutos ou 0,1666668 graus $(\sim 18,5 \mathrm{~km})$.

No caso do produto TRMM 3B43, os mapas mensais foram obtidos com valores de precipitação em mm hora-1 ${ }^{-1}$ no intervalo de 1998 a 2018. O banco de dados TRMM 3B43 é calibrado a partir de dados de pluviômetros distribuídos na superfície terrestre (MACRITCHIE, 2015).

Considerando o WORLDCLIM os valores foram obtidos em mapas de médias climatológicas de cada mês (1960 a 1990) em mm mês ${ }^{-1}$. Os valores de precipitação dos mapas foram obtidos, aproximadamente, nas mesmas 
coordenadas do TRMM 3B43 para ser possível a comparação entre os dados após a modelagem.

Os dados do WORLDCLIM foram modelados inicialmente por Hijmans et al. (2005) a partir de dados de precipitação em uma rede global de pluviômetros utilizando o período de 1950-2000. Esses mapas foram produzidos na resolução espacial de $30 \operatorname{arc.s}^{-1}(\sim 1 \mathrm{~km})$ por técnicas de interpolação geoestatística utilizando mapas de latitude, longitude e altitude como variáveis independentes.

Após a obtenção dos dois bancos de dados para a área de estudo, estes foram convertidos ao formato vetorial de pontos (shapefile). $\mathrm{Na}$ sequência, e por sua vez, os arquivos vetoriais foram subdivididos, aleatoriamente, considerando todo o quadrante amostral em dois conjuntos distintos de dados: o primeiro (1) foi utilizado para a realização do mapeamento e o segundo (2) para a validação cruzada (conjunto de teste). $\mathrm{O}$ mapeamento foi realizado a partir da técnica de interpolação (geoestatística) pelo método da krigagem ordinária (e.g. BARNI et al., 2016), obtendo-se um mapa de precipitação média de cada mês para toda a área de estudo com $500 \mathrm{~m}$ de resolução espacial, equivalente a área de 25 hectares (ha). A krigagem ordinária é uma técnica de interpolação geoestatística robusta, fácil de aplicar e facilita a interpretação dos resultados (CAMBARDELLA et al., 1994; BELLO-PINEDA; HERNÁNDES-STEFANONI, 2007; BOHLING, 2005; ALVARES et al., 2011; 2014; BARNI et al., 2016). Um semivariograma foi modelado para cada mês em particular, em que os parâmetros observados em cada modelo foram o efeito pepita (erro aleatório, intrínseco à estrutura e distribuição espacial dos dados), alcance (medida que informa até onde o modelo controla as estimativas) e patamar ou sela (limite a partir do qual as estimativas dos valores modelados se tornam aleatórias (e.g. ALVARES et al., 2011; 2014; BARNI et al., 2016). Todos os modelos executados durante a krigagem dos pontos, tanto para os dados do TRMM quanto do WORLDCLIM foram exponenciais, sendo utilizados oito (8) vizinhos mais próximos (mínimo de 4) para estimar o valor da precipitação em um determinado local não amostrado. Como forma de avaliar a Dependência Espacial - DE da variável modelada em cada modelo teórico utilizou-se a relação do efeito pepita com o patamar exprimindo-se esse índice em porcentagem, sendo quanto menor a relação maior é a DE\% (CAMBARDELLA et al. 1994).

Após a confecção de cada mapa mensal de precipitação para a área de estudo foi realizada a extração de um mapa mensal de precipitação abrangendo apenas os limites do Estado. $\mathrm{Na}$ sequência também foram confeccionados mapas de precipitação anual apenas para os dados do TRMM 3B43. Para os dados do WORLDCLIM foi possível apenas representar um ano "médio", somando-se as médias mensais para compor a precipitação desse ano. O manuseio da base de dados e a aplicação das técnicas de geoestatística, incluindo a validação, foram realizadas em ambiente computacional do programa de Sistema de Informação Geográfica - SIG do software livre Quantum Gis - QGis Desktop 2.18.15 (https://www.qgis.org/). Os mapas foram produzidos a partir de coordenadas planas, na projeção Universal Transversa de Mercator - UTM, zona 20 norte e no datum WGS 1984.

\section{Validação cruzada e independente}

A validação cruzada foi realizada a partir da coleta dos valores estimados pela modelagem nos locais dos pontos (coordenadas geográficas) que foram reservados para a validação confrontandose estes valores (preditos) com os valores observados no conjunto reserva. Para a avaliação dos parâmetros obtidos (média, erro padrão, desvio padrão e coeficiente de determinação - $\mathrm{R}^{2}$ ) foram utilizadas análises estatísticas (análise de regressão simples e teste t) comparando os valores estimados (preditos) pelo modelo com os valores observados no conjunto de teste. Todas as análises foram executadas no software livre R 3.6 (R CORE TEAM, 2019), no nível de 95\% de confiança estatística (erro tipo I: $\alpha=0,05$ ).

A validação independente dos mapeamentos consistiu da comparação dos valores de precipitação $\left(\mathrm{mm}\right.$ mês $\left.{ }^{-1}\right)$ de 59 postos pluviométricos com os valores estimados pelos modelos (mapas) obtidos nas mesmas coordenadas geográficas e considerando-se os três (3) tipos climáticos existentes no Estado: $A f$ $(\mathrm{n}=18), A m(\mathrm{n}=16)$ e $A w(\mathrm{n}=25)$. Para a avaliação dos parâmetros obtidos observou-se os valores dos coeficientes de correlação $(r)$ de Pearson (DANCEY; REIDY, 2006; FIGUEIREDO-FILHO; SILVA JR., 2009) e a significância estatística da análise de variância (ANOVA). No entanto, na avaliação dos mapas médios anuais, foram utilizados os valores anuais dos 59 postos, sem considerar os tipos climáticos, presumindo-se que esse seria uma mistura ou combinação da atuação climática distribuída no período.

O banco de dados com os 59 postos pluviométricos reuniu informações provenientes de Barbosa (1997) coletadas de múltiplas agências governamentais do Brasil (por exemplo, ANA, INMET, IBAMA, SINDA/INPE e 
EMBRAPA), representando 56 postos, além de dois da Venezuela e um da Guiana (Wheatherbase) (Fluxograma 1). O número de meses em cada posto utilizado para a validação variou de 17 (início em junho de 1988 a outubro de 1989), registrados em Apiaú, município de
Mucajaí, durante 1.052 meses (janeiro de 1910 a dezembro de 2011), registrados na estação meteorológica de Boa Vista. O número médio registrado foi de 213,3 meses ( $\sim 18$ anos), considerando todos os 59 postos pluviométricos.

Fluxograma 1 - Passos necessários para a validação independente dos mapeamentos.

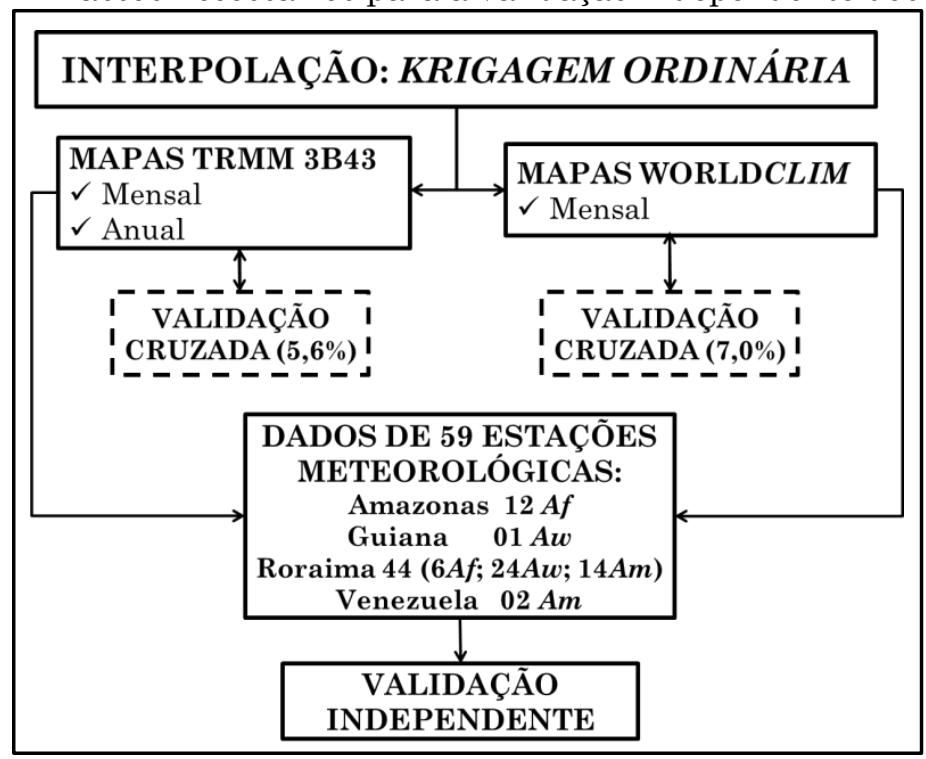

Organizado pelos autores, 2020.

\section{RESULTADOS E DISCUSSÃO}

No geral, a modelagem da distribuição espacial da precipitação sobre a superfície do Estado de Roraima utilizando os dados do TRMM e do WORLDCLIM apresentaram bons resultados, como atestam os parâmetros avaliados a seguir.

Os semivariogramas modelados a partir dos dados do TRMM, dos meses de fevereiro, junho e novembro não registraram efeito pepita, indicando que seus valores apresentaram pouco ou nenhum erro aleatório dentro dos limites do alcance. Os meses de maio $(51,0)$ e abril $(43,8)$, respectivamente, apresentaram os maiores valores de efeitos pepita e, teoricamente, seus modelos apresentaram maior número de erros aleatórios (Gráfico 1A).

Considerando a modelagem do semivariograma a partir dos dados do WORLDCLIM, ao contrário dos resultados do TRMM, todos os meses apresentaram efeito pepita. Os meses de maio $(69,5)$ e junho $(63,9)$, respectivamente, apresentaram os maiores valores de efeitos pepita, enquanto o menor valor $(5,8)$ foi apresentado pelo mês de fevereiro (Gráfico 1B).

Gráfico 1 - Modelo do semivariograma das médias mensais de precipitação para Roraima obtido pelo produto TRMM 3B43 (A) e pelos dados do WORLDCLIM (B). Obs.: as curvas estão apresentadas na sequencia do maior valor para o menor valor de sela para cada mês modelado.

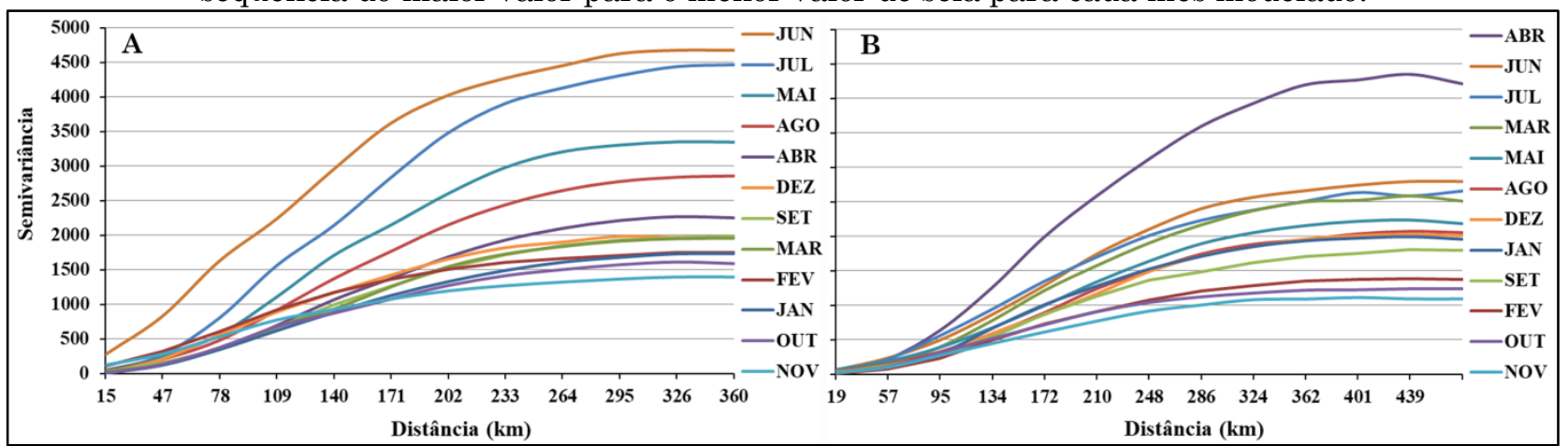

Organizado pelos autores, 2020. 
A distância média encontrada do alcance, considerando os modelos do TRMM 3B43, foi de $275,2 \mathrm{~km}$, contra $287,6 \mathrm{~km}$ para os semivariogramas modelados pelo WORLDCLIM. Este valor foi apenas 4,5\% maior do que o alcance médio atingido pela modelagem dos dados do TRMM. Além desse limite a modelagem dos dados se torna aleatória (Tabela 1).

Estes resultados indicam que os dados, tanto do TRMM como do WORLDCLIM, foram bem estruturados, decorrendo em função da regularidade da grade de pontos. Os baixos índices obtidos entre o efeito pepita e o patamar ou sela, indica forte dependência espacial (DE) da variável aleatória modelada (CAMBARDELLA et al., 1994), o que é um fator desejável na modelagem geoestatística (MELLO; OLIVEIRA, 2016).

Tabela 1 - Parâmetros da modelagem do semivariograma da krigagem ordinária para a precipitação mês a mês obtidas do produto TRMM 3B43 e do WORLDCLIM. DE= Dependência Espacial.

TRMM 3B43

\begin{tabular}{lcccccccc}
\hline Mês & $\begin{array}{c}\text { Efeito } \\
\text { pepita }\end{array}$ & $\begin{array}{c}\text { Alcance } \\
(\mathbf{k m})\end{array}$ & Sela & $\boldsymbol{D E} \%$ & $\begin{array}{c}\text { Efeito } \\
\text { pepita }\end{array}$ & $\begin{array}{c}\text { Alcance } \\
(\mathbf{k m})\end{array}$ & Sela & $\boldsymbol{D E} \%$ \\
\hline JAN & 4,7 & 274,6 & $1.775,3$ & 0,27 & 14,3 & 326,9 & $2.004,1$ & 0,71 \\
FEV & 0,0 & 306,0 & $1.761,2$ & 0,00 & 5,8 & 328,2 & $1.404,1$ & 0,41 \\
MAR & 36,4 & 287,3 & $1.963,9$ & 1,86 & 17,8 & 371,9 & $2.593,7$ & 0,69 \\
ABR & 43,8 & 270,2 & $2.273,5$ & 1,93 & 47,4 & 373,4 & $4.337,2$ & 1,09 \\
MAI & 51,0 & 246,6 & $3.362,4$ & 1,52 & 69,5 & 250,0 & $2.205,3$ & 3,15 \\
JUN & 0,0 & 300,0 & $4.771,4$ & 0,00 & 63,9 & 243,5 & $2.764,5$ & 2,31 \\
JUL & 20,9 & 294,3 & $4.533,5$ & 0,46 & 51,2 & 276,6 & $2.624,1$ & 1,95 \\
AGO & 41,0 & 274,8 & $2.894,5$ & 1,42 & 42,4 & 248,2 & $2.055,1$ & 2,06 \\
SET & 34,5 & 264,6 & $1.987,9$ & 1,74 & 24,4 & 273,1 & $1.808,1$ & 1,35 \\
OUT & 5,1 & 281,2 & $1.615,1$ & 0,31 & 22,5 & 224,2 & $1.226,9$ & 1,83 \\
NOV & 0,0 & 264,1 & $1.417,5$ & 0,00 & 23,3 & 239,2 & $1.111,3$ & 2,09 \\
DEZ & 14,0 & 239,2 & $2.012,3$ & 0,69 & 39,5 & 296,4 & $2.028,1$ & 1,95 \\
\hline
\end{tabular}

De acordo com os mapas mensais de precipitação modelados, tanto pelo TRMM 3B43 como pelo WORLDCLIM, a parte central, de norte a sul, e a parte centro-leste, apresentaram as maiores oscilações da precipitação ao longo do ano (Figuras 1 e 2). Essas perturbações, provavelmente, estão relacionadas ao clima de monções $(\mathrm{Am})$, que influencia as chuvas no Estado, principalmente em anos de La Niña (GRIMM, 2003).

A região correspondendo às savanas de Roraima, região nordeste do Estado, foi corretamente caracterizada nos mapas por ambos os mapeamentos. Esta é caracterizada por baixa pluviosidade durante todo o ano quando comparado com a precipitação sobre áreas de florestas, e de atuação do clima $A w$ (BARBOSA, 1997).

Por outro lado, nas regiões de maior pluviosidade (sul, sudeste, sudoeste e extremo norte) se encontram as florestas, caracterizadas por possuir grande estoque de biomassa (BARNI et al., 2016). Por exemplo, na região sul, próximo à linha do equador, atua o clima equatorial $(A f)$ caracterizado por chuvas torrenciais na estação chuvosa e nos meses com médias de menor pluviosidade a precipitação permanece entre 100 $\mathrm{mm}$ a $150 \mathrm{~mm}$ mensais.

Intercalado aos climas Aw e Af, atua o clima de monção (Am). Este tipo climático influencia principalmente uma faixa abrangendo a região centro sul e noroeste do Estado. Este clima pode estar relacionado com a inversão climática que é observada ao início do mês de setembro, quando a precipitação começa a diminuir no norte de Roraima, mas na região correspondente ao hemisfério sul, a temporada das chuvas está apenas começando (GRIMM, 2003). A inversão climática coincide com o retorno da Zona de Convergência Intertropical - ZCIT para a região próxima do Equador após o término do verão no hemisfério norte (e.g. WU et al., 2019).

As Tabelas 2 e 3 apresentam os resultados da validação cruzada realizada a partir do banco de dados de teste do TRMM 3B43 e do WORLDCLIM, respectivamente. Considerando as duas análises os menores coeficientes de determinação encontrados foram registrados no 
mês de maio, sendo o $\mathrm{R}^{2}$ Ajustado $=0,9745$ calculado para o TRMM 3B43 e $\mathrm{R}^{2}$ Ajustado $=0,9256$ para o WORLDCLIM. Por outro lado, os maiores valores de $\mathrm{R}^{2}$ ajustado foram registrados nos meses de junho $(0,9963)$ para o TRMM 3B43 e fevereiro $(0,9961)$ para o WORLDCLIM.

Figura 1 - Distribuição da precipitação média mensal em Roraima a partir dos dados TRMM 3B43.

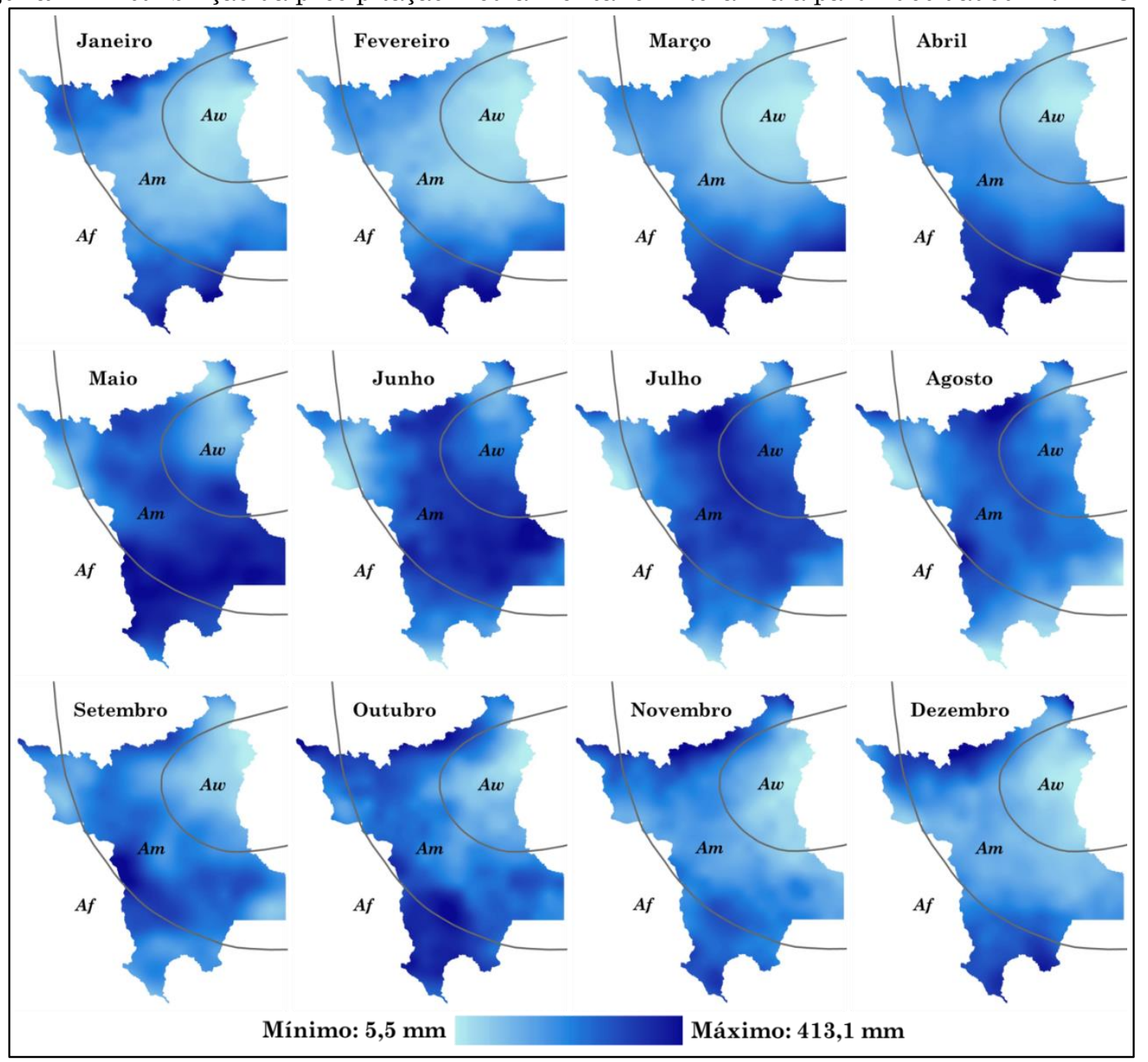

Organizado pelos autores, 2020.

\section{Validação independente}

A validação independente utilizando a precipitação ocorrida nas regiões de domínio dos tipos climáticos indicou forte correlação entre os valores observados e os valores estimados pelos modelos (Tabela 4). De acordo com a análise de variância $(p=0,4606)$ não houve diferença significativa entre os valores observados nos postos pluviométricos e os valores estimados pelos modelos nas mesmas coordenadas geográficas no nível de $95 \%$ de confiança estatística.
As maiores taxas de pluviosidade para $A f$ foram registradas nos meses de março a agosto, independente do modelo, com maior pico em maio. Os climas $A m$ e $A w$ apresentaram o maior pico de precipitação em junho, sendo o intervalo de maior pluviosidade observado de abril a setembro. A comparação das médias mensais observadas e estimadas (Anova) entre os tipos climáticos (Gráfico 2A, 2B e 2C) e dentro (Gráfico $2 \mathrm{D}, \quad 2 \mathrm{E}$ e $2 \mathrm{~F})$, não apresentou diferença significativa no nível de $95 \%$ de confiança estatística. 
Figura 2 - Distribuição da precipitação média mensal em Roraima a partir dos dados WORLDCLIM.

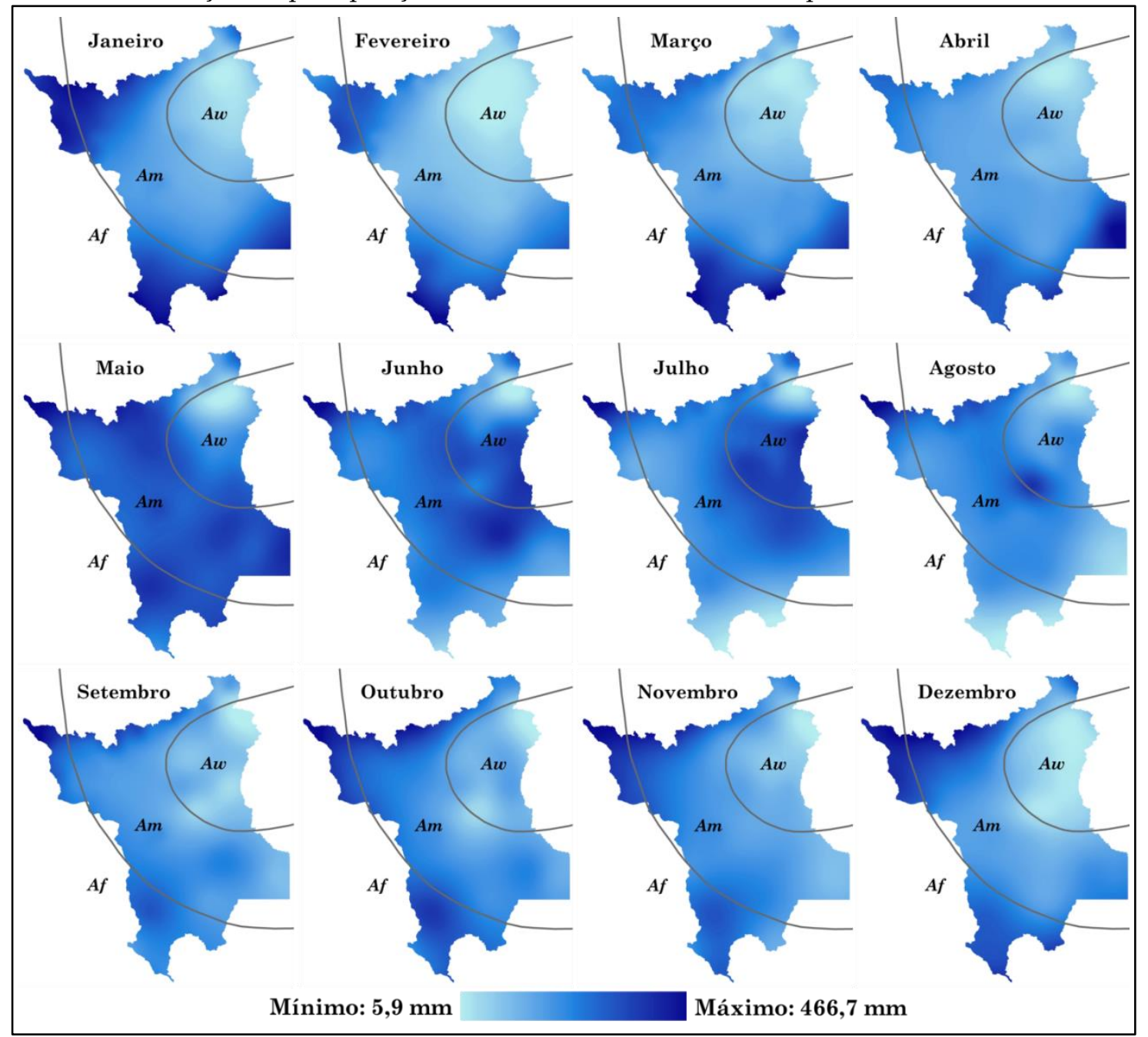

Organizado pelos autores, 2020.

Não foram observadas diferenças significativas (Anova: $p=0,2526$ ) entre os valores médios $(1.951,1 \mathrm{~mm})$ observados nas 59 estações meteorológicas comparados com os valores de um ano médio estimados pelos dados do TRMM 3B43 $(1.925,2 \mathrm{~mm})$ e do ano médio estimado a partir dos dados do WORLDCLIM $(1.831,5 \mathrm{~mm})$. Podese notar, a partir do gráfico 3 , que os dados observados nas estações meteorológicas apresentaram uma maior amplitude de variação enquanto os dados do TRMM 3B43 apresentou a menor amplitude dentre os três bancos de dados comparados (Gráfico 3). Este comportamento deve-se à origem dos dados TRMM 3B43 que são derivados de reanálises (PRAKASH et al., 2016; WOLFF, et al., 2005), diminuindo significativamente os erros e aproximando os valores em torno da média, enquanto os dados das estações estiveram sujeitos às variações estocásticas ou aleatórias naturais da precipitação. $\mathrm{O}$ mesmo pode-se inferir sobre os dados do WORLDCLIM, embora utilizem métodos diferentes para a estimação dos valores nos pontos amostrados. 
Tabela 2 - Resultado da validação cruzada entre os valores observados (Média_O) pelo TRMM 3B43 e os preditos (Média_P) pela krigagem ordinária em 75 pontos $(5,6 \%)$ reservados.

\begin{tabular}{lccccc|ccc}
\hline & \multicolumn{4}{c}{ Análise de Regressão } & \multicolumn{3}{c}{ Teste t } \\
\hline & Média_O & Média_P & Erro pad & $\mathbf{R}^{2}-\boldsymbol{A} \boldsymbol{j}$. & $\boldsymbol{p}$ & Desv pad & \% & $\boldsymbol{p}$ \\
\hline JAN & 154,7 & 155,1 & 6,1423 & 0,9941 & $<0,0000$ & 80,1 & 51,8 & 0,9754 \\
FEV & 162,7 & 162,5 & 6,7872 & 0,9942 & $<0,0000$ & 88,8 & 54,6 & 0,9903 \\
MAR & 213,6 & 214,7 & 8,3671 & 0,9948 & $<0,0000$ & 115,5 & 54,1 & 0,9544 \\
ABR & 272,4 & 272,9 & 7,7462 & 0,9864 & $<0,0000$ & 66,2 & 24,3 & 0,9633 \\
MAI & 342,2 & 340,9 & 10,1960 & 0,9745 & $<0,0000$ & 64,3 & 18,8 & 0,9056 \\
JUN & 281,8 & 281,9 & 6,5359 & 0,9963 & $<0,0000$ & 108,6 & 38,5 & 0,9939 \\
JUL & 249,9 & 250,3 & 7,4968 & 0,9961 & $<0,0000$ & 121,0 & 48,4 & 0,9823 \\
AGO & 193,1 & 193,0 & 7,1944 & 0,9963 & $<0,0000$ & 119,5 & 61,9 & 0,9951 \\
SET & 137,2 & 138,5 & 7,9510 & 0,9908 & $<0,0000$ & 83,7 & 61,0 & 0,9200 \\
OUT & 134,1 & 132,9 & 7,5358 & 0,9866 & $<0,0000$ & 65,9 & 49,2 & 0,9149 \\
NOV & 139,4 & 139,2 & 7,5983 & 0,9847 & $<0,0000$ & 62,2 & 44,6 & 0,9852 \\
DEZ & 155,5 & 155,3 & 7,3675 & 0,9885 & $<0,0000$ & 68,7 & 44,2 & 0,9885 \\
\hline
\end{tabular}

Tabela 3 - Resultado da validação cruzada entre os valores observados (Média_O) pelo WORLDCLIM e os preditos (Média_P) pela krigagem ordinária em 124 pontos $(7,0 \%)$ reservados.

\begin{tabular}{lccccc|ccc}
\hline & \multicolumn{4}{c}{ Análise de Regressão } & \multicolumn{3}{c}{ Teste t } \\
\hline & Média_O & Média_P & Erro pad & $\mathbf{R}^{2}$-Aj. & $\boldsymbol{p}$ & Desv pad & \% & $\boldsymbol{p}$ \\
\hline JAN & 168,3 & 168,1 & 7,6683 & 0,9914 & $<0,0000$ & 83,1 & 49,4 & 0,9857 \\
FEV & 155,4 & 155,7 & 4,9875 & 0,9961 & $<0,0000$ & 80,3 & 51,7 & 0,9753 \\
MAR & 204,1 & 204,2 & 7,1710 & 0,9939 & $<0,0000$ & 91,9 & 45,0 & 0,9942 \\
ABR & 253,7 & 253,7 & 8,9530 & 0,9877 & $<0,0000$ & 81,2 & 32,0 & 0,9991 \\
MAI & 314,2 & 312,7 & 14,7359 & 0,9256 & $<0,0000$ & 55,2 & 17,6 & 0,8376 \\
JUN & 267,5 & 265,9 & 13,9233 & 0,9716 & $<0,0000$ & 84,8 & 31,7 & 0,8829 \\
JUL & 221,3 & 220,3 & 12,5603 & 0,9779 & $<0,0000$ & 85,6 & 38,7 & 0,9299 \\
AGO & 182,0 & 181,0 & 8,2018 & 0,9899 & $<0,0000$ & 83,0 & 45,6 & 0,9270 \\
SET & 134,5 & 133,6 & 6,7628 & 0,9887 & $<0,0000$ & 64,6 & 48,0 & 0,9129 \\
OUT & 129,2 & 128,7 & 5,0614 & 0,9916 & $<0,0000$ & 55,4 & 42,9 & 0,9483 \\
NOV & 134,2 & 133,5 & 7,3878 & 0,9772 & $<0,0000$ & 49,2 & 36,7 & 0,9120 \\
DEZ & 156,3 & 155,8 & 9,9103 & 0,9758 & $<0,0000$ & 64,3 & 41,2 & 0,9590 \\
\hline
\end{tabular}

A partir dos dados do TRMM 3B43 foi possível fazer a distribuição espacial da precipitação anual $(\mathrm{n}=21)$ para o Estado de Roraima e arredores. É interessante notar que a precipitação anual segue um padrão intercalando períodos úmidos de quatro a cinco anos e períodos secos de dois a três anos. Esse padrão, aparentemente, coincide com a ocorrência de anos de El Niño e La Niña, apresentando grande influência no regime pluviométrico do Estado (SILVA et al., 2015) e da Amazônia como um todo (Figura 3).

No intervalo de 1998 a 2018 foram registrados 10 anos que registraram precipitações acima da média de 1.925,2 $\pm 339,7$ mm (+1,0 desvio padrão) e 10 abaixo da média (1,0 desvio padrão) para o período, enquanto o ano de 2004, praticamente, coincidiu com a média, chovendo 1.940,3 mm (Gráfico 4). Apesar da forte precipitação registrada em 2006 e 2007, esses anos foram classificados como de El Niño fraco (SILVA et al., 2015). 
Tabela 4 - Análise de correlação de Pearson (r) relacionando os valores observados nas 59 estações com os valores estimados pelos modelos nas mesmas coordenadas geográficas. Os tipos climáticos $(A f, A m$ e $A w$ ) seguidos de $\mathrm{E}, \mathrm{T}$ e $\mathrm{W}$ indicam os valores observados pelas estações (E) e os valores preditos pelo TRMM 3B43 (T) e pelo WORLDCLIM (W). Valores em negrito indicam forte correlação $(r>0,7000)$ entre os valores observados e preditos dentro de cada tipo climático.

\begin{tabular}{lccccccccc}
\hline & $\boldsymbol{A f \_} \boldsymbol{E}$ & $\boldsymbol{A f} \boldsymbol{T}$ & $\boldsymbol{A f} \boldsymbol{f}_{-} \boldsymbol{W}$ & $\boldsymbol{A} \boldsymbol{m}_{-} \boldsymbol{E}$ & $\boldsymbol{A m} \_\boldsymbol{T}$ & $\boldsymbol{A} \boldsymbol{m}_{-} \boldsymbol{W}$ & $\boldsymbol{A} \boldsymbol{w}_{-} \boldsymbol{E}$ & $\boldsymbol{A} \boldsymbol{w}_{-} \boldsymbol{T}$ & $\boldsymbol{A} \boldsymbol{w}_{-} \boldsymbol{W}$ \\
\hline Af_E & 1,0000 & & & & & & & & \\
Af_T & $\mathbf{0 , 9 8 6 5}$ & 1,0000 & & & & & & & \\
Af_W & $\mathbf{0 , 9 9 5 5}$ & 0,9916 & 1,0000 & & & & & & \\
Am_E & 0,7711 & 0,7585 & 0,7511 & 1,0000 & & & & & \\
Am_T & 0,7989 & 0,7897 & 0,7805 & $\mathbf{0 , 9 9 7 2}$ & 1,0000 & & & & \\
Am_W & 0,7862 & 0,7705 & 0,7674 & $\mathbf{0 , 9 9 5 3}$ & 0,9951 & 1,0000 & & & \\
Aw_E & 0,7253 & 0,7151 & 0,7041 & 0,9969 & 0,9898 & 0,9903 & 1,0000 & & \\
Aw_T & 0,7275 & 0,7250 & 0,7107 & 0,9956 & 0,9918 & 0,9896 & $\mathbf{0 , 9 9 7 5}$ & 1,0000 & \\
Aw_W & 0,6737 & 0,6654 & 0,6530 & 0,9844 & 0,9735 & 0,9815 & $\mathbf{0 , 9 9 3 5}$ & 0,9895 & 1,0000 \\
\hline
\end{tabular}

Por outro lado, os anos de 2001, 2009, 2014 e 2015 apresentaram precipitação anômala para menos, chovendo um desvio padrão abaixo da média do período. Esses anos foram marcados por fortes secas no Estado.

É importante destacar que a análise anual prejudica uma melhor avaliação dos períodos secos (de setembro de um ano até março do ano seguinte) e consequentemente, da influência dos fenômenos climáticos em Roraima (e.g.
MARENGO, 1992; GRIMM, 2003). Por exemplo, o intervalo iniciado em outubro / novembro de 2015 e finalizado no início de abril de 2016, foi caracterizado como de influência de um dos El Niños mais severos já ocorridos na Amazônia (FONSECA et al., 2017; SILVA JR et al., 2019), sendo considerado mais forte do que o do biênio 1997-98, onde foram incendiados mais de 11.000 $\mathrm{km}^{2}$ de floresta primária em Roraima (BARBOSA; FEARNSIDE, 1999).

Gráfico 2 - Precipitação média mensal observada e estimada no local das estações meteorológicas considerando os três tipos climáticos: $A f(\mathrm{n}=18), A m(\mathrm{n}=16)$ e $A w(\mathrm{n}=25)$. Frequência da precipitação mensal dos três tipos climáticos a partir das estações meteorológicas (A: E), do TRMM (B: T) e do

WORLDCLIM (C: W). Em (D), (E) e (F) frequência da precipitação mensal em função dos tipos climáticos e dos valores observados nas estações e os modelados pelo TRMM e WORLDCLIM.

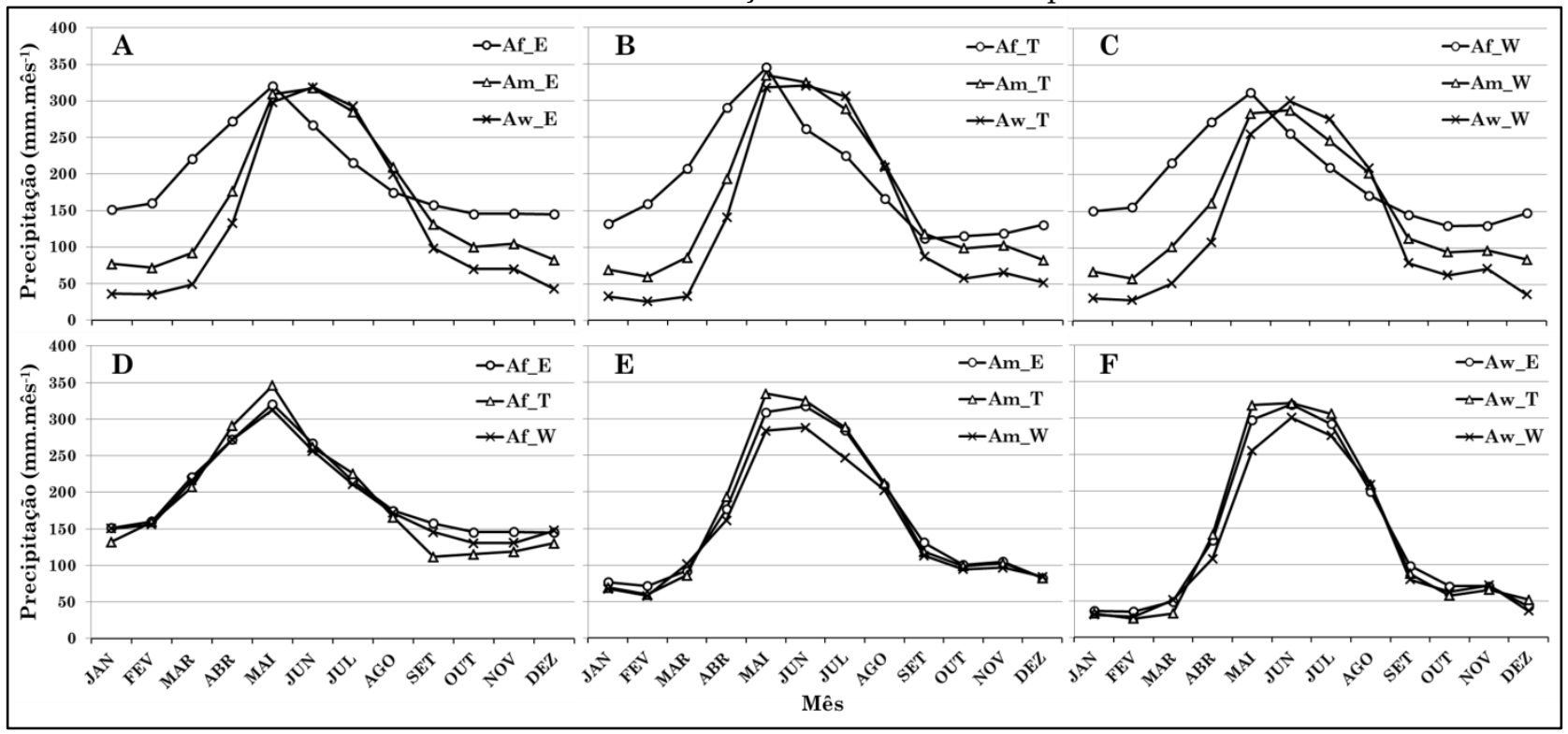

Organizado pelos autores, 2020. 
Gráfico 3 - Comparação entre os valores anuais observados (Estações) e os valores preditos ou modelados pelo TRMM (TRMM 3B43) e pelo WORLDCLIM (WCLIM), nos 59 postos meteorológicos localizados na área de estudo. As barras verticais indicam os quartis extremos das amostras (primeiro e quarto, respectivamente). A linha central representa a média e as linhas fechando o box delimitam o início do segundo e o final do terceiro quartil, respectivamente. As letras minúsculas iguais indicam que não houve diferença significativa entre as médias, no nível de $99 \%$ de confiança estatística $(\alpha=0,01)$.

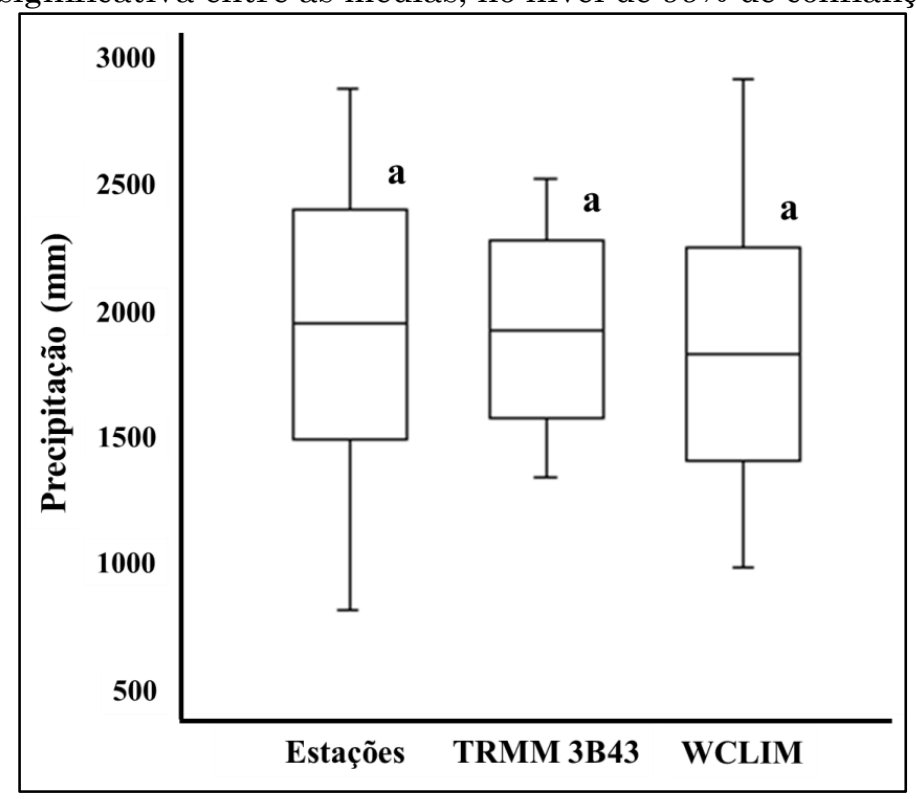

Organizado pelos autores, 2020.

A análise dos parâmetros da krigagem ordinária (curvas dos modelos teóricos, efeito pepita, alcance e sela) referente aos mapas anuais, está apresentada no material suplementar (Gráfico S1 e Tabela S1). Considerando a validação cruzada, realizada a partir da modelagem dos mapas anuais do TRMM 3B43, estes apresentaram altos desempenhos se considerarmos os valores do coeficiente de determinação ( $\mathrm{R}^{2}$ ajustado), todos eles acima de $92,4 \%$ de concordância estatística.
Ainda considerando este quesito, pelo menos nove (9) modelos teóricos anuais (42,9\%) foram superiores a $97 \%$ de explicação da variação dos valores preditos (Tabela 5). Realizando o mesmo procedimento acima, aplicando um modelo de regressão simples $(n=21)$ com as médias observadas (x) e as estimadas (y), obteve-se quase $100 \%$ de concordância entre os valores $\left(R^{2}\right.$ ajustado=0,9986; $p<0,0001$ ). 
Figura 3 - Mapas de precipitação anuais modelados a partir dos dados do TRMM 3B43 para Roraima (municípios do Estado) e arredores. Os quadros coloridos ao redor do ano nos mapas representam a influência climática predominante. Assim, a coloração preta=Anos normais; amarela= La Niña e; vermelha= El Niño (SILVA et al., 2015).
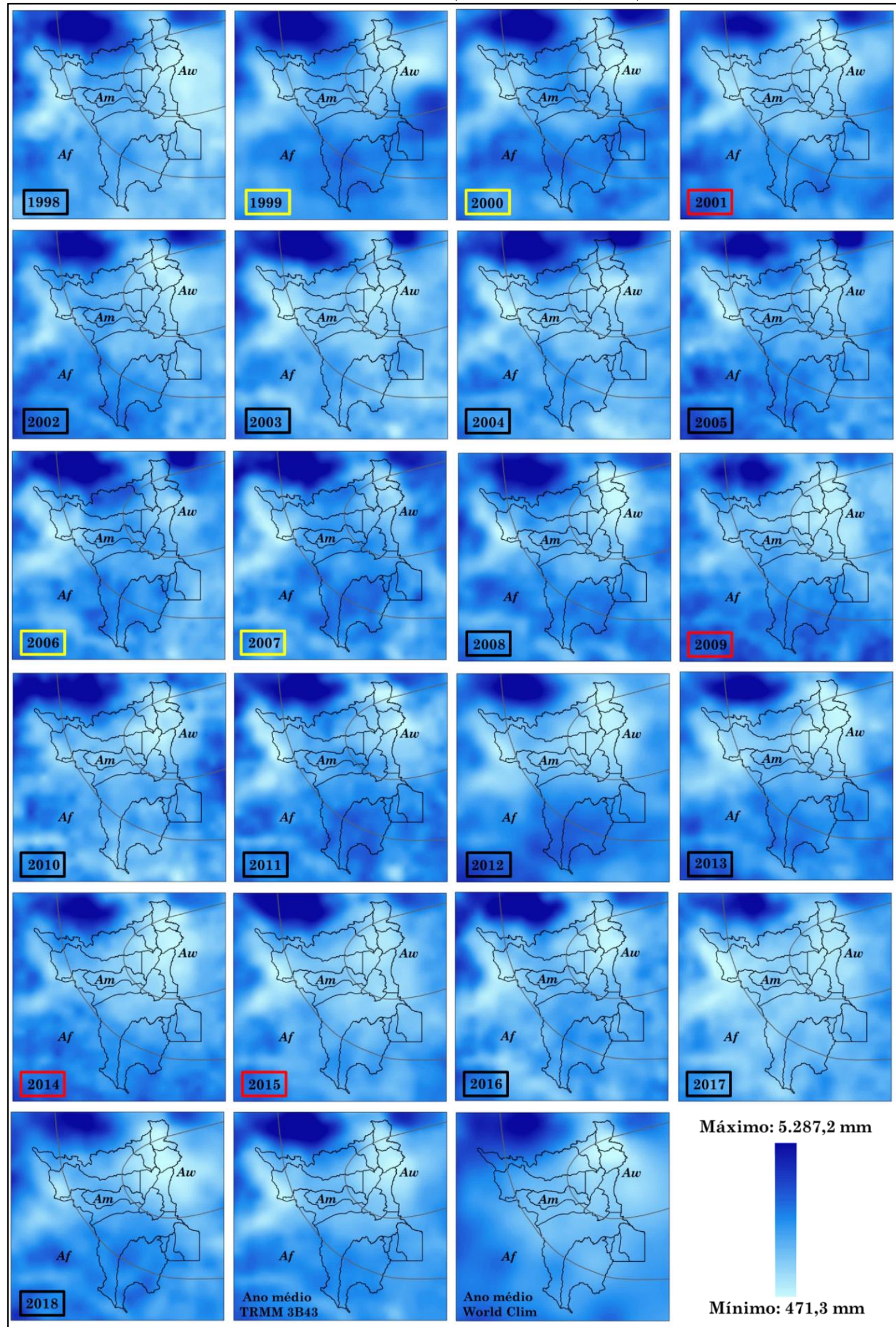

Máximo: 5.287,2 mm

Organizado pelos autores, 2020. 
Gráfico 4 - Distribuição anual da precipitação em Roraima a partir de dados do TRMM 3B43. A linha cheia representa a média, enquanto a linha tracejada (M+DP) representa o desvio padrão do período somado à média e a linha pontilhada (M-DP) representa a média menos o desvio padrão.

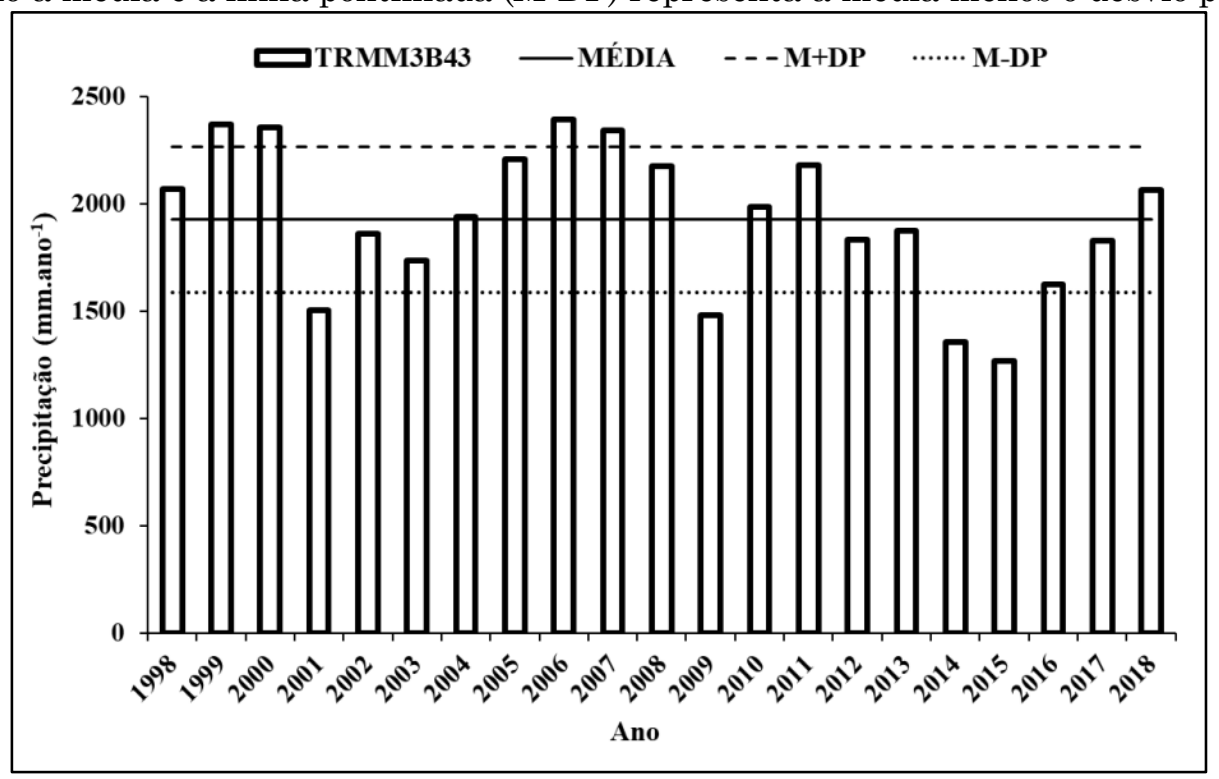

Organizado pelos autores, 2020.

Tabela 5 - Resultado da validação cruzada entre os valores observados (Média_O) pelo TRMM e os preditos (Média_P) em cada ano em 75 pontos $(5,6 \%)$ reservados para a krigagem ordinária.

\begin{tabular}{cccccc|ccc}
\hline & & \multicolumn{3}{c|}{ Análise de Regressão } & \multicolumn{3}{c}{ Teste t } \\
\hline & Média_O & Média_P & Erro pad & $\mathbf{R}^{2}$ Aj. & $\boldsymbol{p}$ & Desv pad & \% & $\boldsymbol{p}$ \\
\hline $\mathbf{1 9 9 8}$ & 2380,8 & 2389,0 & 90,7 & 0,9704 & $<0,0000$ & 523,7 & 22,0 & 0,9243 \\
$\mathbf{1 9 9 9}$ & 2695,6 & 2706,8 & 98,2 & 0,9553 & $<0,0000$ & 464,8 & 17,2 & 0,8824 \\
$\mathbf{2 0 0 0}$ & 2666,0 & 2671,1 & 94,8 & 0,9621 & $<0,0000$ & 490,0 & 18,4 & 0,9494 \\
$\mathbf{2 0 0 1}$ & 2065,5 & 2078,1 & 103,8 & 0,9660 & $<0,0000$ & 565,2 & 27,4 & 0,8920 \\
$\mathbf{2 0 0 2}$ & 2341,0 & 2355,3 & 96,5 & 0,9738 & $<0,0000$ & 595,5 & 25,4 & 0,8833 \\
$\mathbf{2 0 0 3}$ & 2163,5 & 2174,0 & 85,0 & 0,9701 & $<0,0000$ & 483,2 & 22,3 & 0,8950 \\
$\mathbf{2 0 0 4}$ & 2330,8 & 2350,8 & 103,1 & 0,9597 & $<0,0000$ & 511,4 & 21,9 & 0,8106 \\
$\mathbf{2 0 0 5}$ & 2561,9 & 2562,6 & 86,4 & 0,9634 & $<0,0000$ & 454,8 & 17,8 & 0,9917 \\
$\mathbf{2 0 0 6}$ & 2599,4 & 2604,1 & 89,2 & 0,9640 & $<0,0000$ & 471,5 & 18,1 & 0,9517 \\
$\mathbf{2 0 0 7}$ & 2538,3 & 2562,4 & 90,4 & 0,9528 & $<0,0000$ & 411,9 & 16,2 & 0,7209 \\
$\mathbf{2 0 0 8}$ & 2649,9 & 2652,0 & 125,4 & 0,9242 & $<0,0000$ & 461,0 & 17,4 & 0,9777 \\
$\mathbf{2 0 0 9}$ & 2208,2 & 2203,3 & 121,2 & 0,9647 & $<0,0000$ & 646,3 & 29,3 & 0,9633 \\
$\mathbf{2 0 1 0}$ & 2460,7 & 2464,5 & 102,1 & 0,9564 & $<0,0000$ & 489,9 & 19,9 & 0,9614 \\
$\mathbf{2 0 1 1}$ & 2528,1 & 2516,8 & 93,9 & 0,9554 & $<0,0000$ & 454,9 & 18,0 & 0,8792 \\
$\mathbf{2 0 1 2}$ & 2390,7 & 2405,7 & 109,5 & 0,9706 & $<0,0000$ & 640,3 & 26,8 & 0,8860 \\
$\mathbf{2 0 1 3}$ & 2425,7 & 2436,6 & 112,3 & 0,9591 & $<0,0000$ & 551,4 & 22,7 & 0,9036 \\
$\mathbf{2 0 1 4}$ & 2074,7 & 2093,0 & 98,1 & 0,9775 & $<0,0000$ & 652,8 & 31,5 & 0,8639 \\
$\mathbf{2 0 1 5}$ & 1817,4 & 1822,5 & 90,1 & 0,9701 & $<0,0000$ & 523,5 & 28,8 & 0,9527 \\
$\mathbf{2 0 1 6}$ & 2135,0 & 2143,3 & 78,8 & 0,9778 & $<0,0000$ & 532,3 & 24,9 & 0,9244 \\
$\mathbf{2 0 1 7}$ & 2412,5 & 2416,8 & 74,2 & 0,9829 & $<0,0000$ & 565,0 & 23,4 & 0,9626 \\
$\mathbf{2 0 1 8}$ & 2607,1 & 2601,4 & 71,7 & 0,9819 & $<0,0000$ & 539,4 & 20,7 & 0,9491 \\
\hline
\end{tabular}




\section{CONSIDERAÇÕES FINAIS}

O padrão de precipitação pluviométrica espacial e mensal em Roraima é fortemente influenciado pelos três tipos climáticos existentes. O clima $A f$ apresenta maior pluviosidade entre os meses de março a agosto com maior pico de precipitação em maio. Devido à sua atuação próxima à linha do Equador é o clima que apresenta a maior pluviosidade anual. Por outro lado, $A m$ e $A w$ registram o maior pico pluviométrico em junho, com o período chuvoso compreendendo os meses de abril a setembro. O clima $A w$ apresenta a menor precipitação anual e tem sua área de atuação restrita às áreas de savanas no nordeste do Estado. Estes fatos são marcados pela antecipação das chuvas anuais no sul, retardando a sua chegada por alguns dias / semanas no norte / nordeste do Estado.

De um modo geral, fenômenos climáticos representados por anos de El Niño e La Niña controlam fortemente o clima em Roraima. Provavelmente, a atuação forte dessas anomalias climáticas é favorecida pela posição geográfica do Estado, sendo que ocupa áreas nos dois hemisférios terrestres, influenciando os três tipos climáticos existentes. Os mapas modelados pelos dois bancos de dados tiveram a habilidade de captar essas variações climáticas. Nesse caso, independentemente dos valores atribuídos pelos indicadores de desempenho a cada um deles no estudo, considerou-se que os mapas modelados (tanto pelo TRMM quanto pelo WORCLIM), são igualmente válidos e úteis para representar a variável precipitação no Estado de Roraima e seus arredores, considerando os seus três tipos climáticos.

A krigagem ordinária foi um método efetivo para a modelagem e criação dos mapas de chuvas para o Estado de Roraima e seus arredores. Isso é importante, pois esses mapas oferecem a oportunidade de estabelecer e organizar modelos climáticos no nível municipal. No entanto, há de se destacar que essa sequência metodológica serve apenas como alternativa à carência de pluviômetros na região, concordando que o ideal seja a construção de uma grande rede física de pluviômetros instalados regularmente sobre a superfície, para melhorar a previsibilidade da distribuição espacial das chuvas e prover os tomadores de decisão com informações locais e regionais de qualidade.

\section{AGRADECIMENTOS}

À Universidade Estadual de Roraima - UERR, pelo apoio institucional e logístico para a condução deste estudo. Barbosa, R.I recebeu bolsa produtividade fornecida pelo Conselho Nacional de Pesquisas (CNPq Proc. 304204/2015$3)$.

\section{REFERÊNCIAS}

ALENCAR, A.; NEPSTAD, D.; DIAZ, M. D. V. Forest understory fire in the Brazilian Amazon in ENSO and non-ENSO years: area burned and committed carbon emissions. Earth Interactions, 10, 1-17. 2006. https://doi.org/10.1175/EI150.1

ALVARES, C. A.; STAPE, J. L.; SENTELHAS, P. C.; GONCALVES, J. L. M.; SPAROVEK, G. Koppen's climate classification map for Brazil. Meteorologische Zeitschrift, V. 22, N. $6, \quad$ p. $711-728.2014$. https://doi.org/10.1127/0941-2948/2013/0507

ALVARES, C. A.; GONÇALVES, J. L. M.; VIEIRA, S. R.; SILVA, C. R.; FRANCISCATTE, W. Spatial variability of physical and chemical attributes of some forest soils in southeastern of Brazil. Scientia Agricola (Piracicaba, Braz.) [online]. 2011, v. 68, n. 6. p. 697-705. 2011. https://doi.org/10.1590/S0103-

90162011000600015.

ARAGÃO, L. E. O. C.; MALHI, Y.; ROMANCUESTA, R. M.; SAATCHI, S.; ANDERSON, L. O.; SHIMABUKURO, Y. E. Spatial patterns and fire response of recent Amazonian droughts. Geophysical Research Letters, $34(7) . \quad 2007$. https://doi.org/10.1029/2006GL028946

ARAGÃO, L. E. O. C; SHIMABUKURO, Y. E. The incidence of fire in Amazonian forests with implications for REDD. Science, v. 328, p. 1275-1278.

2010 .

https://doi.org/10.1126/science.1186925

AVITABILE, V.; HEROLD, M.; HEUVELINK, G. B. M.; LEWIS, S. L.; PHILLIPS, O. L.; ASNER, G. P.; ARMSTON, J.; ASHTON, P. S.; BANIN, L.; BAYOL, N.; et al. An integrated pan-tropical biomass map using multiple reference datasets. Global Change Biology, v. 22, n. 4, p. 1406-1420. 2016. https://doi.org/10.1111/gcb.13139

BACCINI, A., GOETZ, S., WALKER, W. et al. Estimated carbon dioxide emissions from tropical deforestation improved by carbondensity maps. Nature Climate Change, v. 2 , p. 182-185. 2012. https://doi.org/10.1038/nclimate1354 
BARBOSA, R. I.; XAUD, M. R.; SILVA, G. F. N.; CATTÂNEO, A. C. Forest Fires in Roraima, Brazilian Amazonia. International Forest Fire News, 28 (jan-jul), p. 51-56. 2003. Disponível

em:

https://pdfs.semanticscholar.org/903d/d1e0114 c6cdefe67c0ebb4fe1b87e95fa22c.pdf. Acesso em: 28 de janeiro de 2020 .

BARBOSA, R. I. Distribuição das chuvas em Roraima, p. 325-335. In: Barbosa, R.I.; Ferreira, E.F.G.; Castellon, E. G. (Eds.). Homem, Ambiente e Ecologia no Estado de Roraima. Instituto Nacional de Pesquisas da Amazônia (INPA), Manaus, Amazonas, Brasil. 1997.

BARBOSA, R. I.; FEARNSIDE, P. M. Incêndios na Amazônia: estimativa da emissão de gases de efeito estufa pela queima de diferentes ecossistemas de Roraima na passagem do evento -El-Niño (1997/1998). Acta Amazonica, v. 29, p. 513-534. 1999. https://doi.org/10.1590/1809-43921999294534

BARNI, P. E.; FEARNSIDE, P. M.; GRAÇA, P. M. L. A. Desmatamento no Sul do Estado de Roraima: padrões de distribuição em função de Projetos de Assentamento do INCRA e da distância das principais rodovias (BR-174 e BR-210). Acta Amazonica, 42(2), 183-192. 2012 . https://doi.org/10.1590/S00445967201200020000

BARNI, P. E.; PEREIRA, V. B.; MANZI, A. O.; BARBOSA, R. I. Deforestation and forest fires in Roraima and their relationship with phytoclimatic regions in the Northern Brazilian Amazon. Environmental Management, v. 55, n. 5, p. 1124-1138. 2015a. https://doi.org/10.1007/s00267-0150447-7

BARNI, P. E.; FEARNSIDE, P. M.; GRAÇA P. M. L. A. Simulating deforestation and carbon loss in Amazonia: impacts in Brazil's Roraima state from reconstructing Highway BR-319 (Manaus-Porto Velho). Environmental Management, v. 55, n. 2, p. 259-278. 2015b. https://doi.org/10.1007/s00267-014-0408-6

BARNI, P. E.; MANZI, A. O.; CONDÉ, T. M.; BARBOSA, R. I.; FEARNSIDE, P. M. Spatial distribution of forest biomass in Brazil's state of Roraima, northern Amazonia. Forest Ecology and Management, v. 377, p. 170 181. 2016. https://doi.org/10.1016/j.foreco.2016.07.010

BARNI, P. E.; SILVA, E. B. R.; SILVA, F. C. F. Incêndios florestais de sub-bosque na zona de florestas úmidas do sul de Roraima: área atingida e biomassa morta. In: Anais do Simpósio Brasileiro de Sensoriamento Remoto. Anais eletrônicos,
Campinas, GALOÁ, p, 6280-6287. 2018. Disponível em: http://marte2.sid.inpe.br/col/sid.inpe.br/marte 2/2017/10.27.15.44.12/doc/59747.pdf. Acesso em: 18 de julho de 2019.

BELLO-PINEDA, J.; HERNÁNDESSTEFANONI, J. L. Comparing the performance of twospatial interpolation methods for creating a digital bathymetric model of theYucatan submerged platform. Pan-American Journal of Aquatic Sciences. v. 2, p. 247-254. 2007. https://www.researchgate.net/publication/252 251187

BOHLING, G. Introduction to Geostatistics and Variograms Analysis. Kansas Geological Survey. 2005. Disponível em: <http://people.ku.edu/ gbohling/cpe940/>. Acesso em: 8 de abril de 2020.

BRANDO, P. M.; SOARES-FILHO, B.; RODRIGUES, L.; ASSUNÇÃO, A.; MORTON, D.; TUCHSCHNEIDER, D.; FERNANDES, E. C. M.; MACEDO, M. N.; OLIVEIRA, U.; COE, M. T. The gathering firestorm in southern Amazonia. Science Advances, v. 6, art. eaay 1632. 2020 . https://doi.org/10.1126/sciadv.aay 1632

BRANDO, P. M.; BALCH, J. K.; NEPSTAD, D. C.; MORTON, D. C.; PUTZ, F. E.; COE, M. T.; SILVÉRIO, D.; MACEDO, M. N.; DAVIDSON, E. A.; NÓBREGA, C. C.; ALENCAR, A.; SOARES-FILHO, B. S. Abrupt increases in Amazonian tree mortality due to drought-fire interactions. Proceedings of the National Academy of Sciences USA, v. 111, n. 17, p. 6347-6352. 2014. https://doi.org/10.1073/pnas.1305499111

CAMBARDELLA, C. A.; MOORMAN, T. B.; PARKIN, T. B.; KARLEN, D. L.; NOVAK, J. M.; TURCO, R. F.; KONOPKA, A. E. Fieldscale variability of soil properties in central Iowa soils. Soil Science Society of America Journal, 58(5), p. 1501-1511. 1994. https://doi.org/10.2136/sssaj1994.0361599500 5800050033x

CAMMELLI, F.; ANGELSEN, A. Amazonian farmers' response to fire policies and climate change. Ecological Economics, 165, 106359. https://doi.org/10.1016/j.ecolecon.2019.106359

CASTRO, G. S. A.; MIRANDA, E. Desafios e oportunidades para o desenvolvimento agropecuário e social em Roraima. Embrapa Monitoramento por Satélite / Grupo de Inteligência Territorial Estratégica - GITE. Disponível em: https://www.embrapa.br/gite/projetos/regiaon 
orte/pdf

/160801_GITE_REGIAO_NORTE_RORAIMA. pdf. Acesso em: 02 de maio de 2020. 2016.

CHEN, F.; LI, X. Evaluation of IMERG and TRMM 3B43 monthly precipitation products over mainland China. Remote Sensing, 8:472. 2016. https://doi.org/10.3390/rs8060472

DANCEY, C.; REIDY, J. Estatística Sem Matemática para Psicologia: Usando SPSS para Windows. Porto Alegre, Artmed. 2006.

FEARNSIDE, P. M. Amazon forest maintenance as a source of environmental services. Anais da Academia Brasileira de Ciências, v. $80, \quad$ p. $101-114$. 2008 . https://doi.org/10.1590/S000137652008000100006

FEARNSIDE, P. M. Serviços ambientais provenientes de florestas intactas, degradadas e secundárias na Amazônia brasileira. In: PERES, C. A., GARDNER, T.A., BARLOW, J., VIEIRA, I.C.G. (Eds.), Conservação da Biodiversidade em Paisagens Antropizadas do Brasil. Editora da Universidade Federal do Paraná, Curitiba, Paraná, pp. 26-57. 2013.

FIGUEIREDO FILHO, D. B.; SILVA JUNIOR, J. A. Desvendando os Mistérios do Coeficiente de Correlação de Pearson (r). Revista Política Hoje, Vol. 18, n. 1. p. 115-146. 2009. Disponível em: https://periodicos.ufpe.br/revistas/politicahoje/ article/view/3852/3156. Acesso em: 11 de agosto de 2019.

FICK, S. E.; HIJMANS R. J. WorldClim 2: New $1-\mathrm{km}$ spatial resolution climate surfaces for global land areas. International Journal of Climatology, 37, 4302-4315. 2017. https://doi.org/10.1002/joc.5086

FONSECA-MORELLO, T.; RAMOS, R.; STEIL, L.; PARRY, L.; BARLOW, J.; MARKUSSON, N.; FERREIRA, A. Queimadas e incêndios florestais na Amazônia brasileira: por que as políticas públicas têm efeito limitado? Ambiente \& Sociedade, v. XX, n. 4 n p. 1940. 2017. https://doi.org/10.1590/18094422asoc0232r1v2042017

FONSECA, M. G.; ANDERSON, L. O.; ARAI, E.; SHIMABUKURO, Y. E.; XAUD, H. A. M.; XAUD, M. R.; MADANI, N.; WAGNER, F. H.; ARAGÃO, L. E. O. C. Climatic and anthropogenic drivers of northern Amazon fires during the 2015-2016 El Niño event. Ecological Applications, v. 27, n. 8, p. 2514-2527. 2017. https://doi.org/10.1002/eap.1628

GRIMM, A. M. The El Niño Impact on the Summer Monsoon in Brazil: Regional Processes versus Remote Influences.
American Meteorological Society, 16, 263-280. 2003. https://doi.org/10.1175/15200442(2003)016<0263:TENIOT>2.0.CO;2

HIJMANS, R. J.; CAMERON, S. E.; PARRA, J. L.; JONES, P. G.; JARVIS, A. Very high resolution interpolated climate surfaces for global land areas. International Journal of Climatology, v.25, 1965-1978. 2005. https://doi.org/10.1002/joc.1276

HUFFMAN, G. J.; ADLER, R. F.; ARKIN, P.; CHANG, A.; FERRARO, R.; GRUBER, A.; JANOWIAK, J.; MCNAB, A.; RUDOLF, B.; SCHNEIDER, U. The Global Precipitation Climatology Project (GPCP) combined precipitation dataset. Bulletin of the American Meteorological Society, 78(1), 5-20. 1997. https://doi.org/10.1175/15200477(1997)078<0005:TGPCPG>2.0.CO;2.

IBGE - INSTITUTO BRASILEIRO DE GEOGRAFIA E ESTATÍSTICA. Roraima: população. Disponível em: https://cidades.ibge.gov.br/brasil/rr/panorama. Acesso em: 03 de maio de 2020.

MACRITCHIE, K. README: Document for the Tropical Rainfall Measurement Mission (TRMM) Version 007. Goddard Earth Sciences Data and Information Services Center (GES DISC). 69p. 2015.

MARENGO, J. A. Interannual variability of surface climate in the Amazon basin. International Journal of Climatology, 12, 853-863. 1992. https://doi.org/10.1002/joc.3370120808

MEDINA, G.; ALMEIDA, C.; NOVAES, E.; GODAR, J.; POKORNY, B. Development conditions for family farming: lessons from Brazil. World Development, 74, 386-396. 2015.

https://doi.org/10.1016/j.worlddev.2015.05.023

MELLO, Y. R.; OLIVEIRA, T. M. N. Análise Estatística e Geoestatística da Precipitação Média para o Município de Joinville (SC). Revista Brasileira de Meteorologia, v. 31, n. $2,229-239.2016$. https://doi.org/10.1590/0102778631220150040

MINISTÉRIO DO DESENVOLVIMENTO AGRÁRIO - MDA. PLANO TERRITORIAL DE DESENVOLVIMETO RURAL SUSTENTÁVEL: Propostas de Políticas Públicas para O Território Sul de Roraima. Disponível em: http://sit.mda.gov.br/download/ptdrs/ptdrs_qu a_territorio091.pdf. Acesso em: 02 de maio de 2020. 2010.

MORTON, D. C.; LE PAGE, Y.; DE-FRIES, R.; COLLATZ, G. J.; HURTT, G. C. Understorey fire frequency and the fate of burned forests 
in southern Amazonia. Philosophical Transactions of Royal Society for Biological Science B, 368, 20120163. 2013. https://doi.org/10.1098/rstb.2012.0163

PASSOW M. J. TRMM Tropical rainfall measuring mission: Bringing remote sensing of precipitation into your classroom. TRMM: Trazendo o sensoriamento remoto de precipitação para sua sala de aula. Terræ Didatica, 6(1):03-08. https://doi.org/10.20396/td.v6i1.8637477

PRAKASH, S.; MITRA, A. K.; PAI, D. S.; AGHAKOUCHAK, A. From TRMM to GPM: How well can heavy rainfall be detected from space? Advances in Water Resources, 88, $1-7$. 2016. https://doi.org/10.1016/j.advwatres.2015.11.00 8

$\mathrm{R}$ DEVELOPMENT CORE TEAM. R: A Language and Environment for Statistical Computing. $\mathrm{R}$ Foundation for Statistical Computing, Vienna, Austria. 2019. $<$ http://www.r-project.org>

SILVA JR., C. H. L.; ANDERSON, L. O.; SILVA, A. L.; ALMEIDA, C. T.; DALAGNOL, R.; PLETSCH, M. A. J. S.; et al. Fire Responses to the 2010 and 2015/2016 Amazonian Droughts. Frontiers in Earth Science, v.7. $16 \mathrm{p}$. 2019. https://doi.org/10.3389/feart.2019.00097

SILVA, C. V. J.; ARAGÃO, L. E. O. C.; BARLOW, J.; ESPÍRITO-SANTO, F.; YOUNG, P. J.; et al. Drought induced Amazonian wildfires instigate a decadal scale disruption of forest carbon dynamics. Philosophical Transactions of Royal Society B, 373: 20180043. 2018. https://doi.org/10.1098/rstb.2018.0043

SILVA, D. A.; SANDER, C.; ARAÚJO JR, A. C. R.; WANKLER, F. L. Análise dos ciclos de precipitação na região de Boa Vista - RR nos anos de 1910 a 2014. Revista Geográfica Acadêmica, v.9, 35-49, 2015. https://doi.org/10.18227/16787226rga.v9i2.3145

STAAL, A.; BERNARDO, M. F.; AGUIAR, A. P. D.; BOSMANS, J. H. C.; FETZER, I.; TUINENBURG, O. A. Feedback between drought and deforestation in the Amazon. Non-peer-reviewed EarthArXiv preprint. 2020. https://doi.org/10.31223/osf.io/8rq4n

TERRAMZ: conhecimento compartilhado para gestão territorial local na Amazônia. Boa Vista, RR: Embrapa Roraima (Folder). Disponível em: <http://ainfo.cnptia.embrapa.br/digital/bitstre am/item /212385/1/TERRAMZ-Folder.pdf>. Acesso em: 04 de maio de 2020. 2020.
WOLFF, D. B.; MARKS, D. A.; AMITAI, E.; SILBERSTEIN, D. S.; FISHER, B. L.; TOKAY, A.; WANG, J.; PIPPITT, J. L. Ground Validation for the Tropical Rainfall Measuring Mission (TRMM). American Meteorological Society, v. 22, 365-380. 2005. https://doi.org/10.1175/JTECH1700.1

WU, C. R.; LIN, Y. F.; QIU, B. Impact of the Atlantic Multidecadal Oscillation on the Pacific North Equatorial Current bifurcation. Scientific Reports, 9, 2162. 2019. https://doi.org/10.1038/s41598-019-38479-w

YANG, Z.; HSU, K.; SOROOSHIAN, S.; XU, X.; BRAITHWAITE, D.; ZHANG, Y.; VERBIST, K. M. J. Merging high-resolution satellitebased precipitation fields and point-scale rain gauge measurements-A case study in Chile. Journal of Geophysical Research: Atmospheres, 122, 5267-5284. 2017. https://doi.org/10.1002/2016JD026177

XAUD, H. A. M.; MARTINS, F. S. R. V.; SANTOS, J. R. Tropical forest degradation by mega-fires in the northern Brazilian Amazon. Forest Ecology and Management, 294: 97-106. 2013.

https://doi.org/10.1016/j.foreco.2012.11.036 